\title{
POLIMERIZAÇÃO DAS PROTEÍNAS DO LEITE POR TRANSGLUTAMINASE: MODIFICAÇÃO DAS PROPRIEDADES FUNCIONAIS E APLICAÇÃO EM PRODUTOS LÁCTEOS
}

CONY GAUCHE*

THAYS TOMAZI**

MARILDE TEREZINHA BORDIGNON-LUIZ***

\begin{abstract}
Este trabalho teve como objetivo destacar as principais características da transglutaminase de origem microbiana (Streptoverticilium mobaraense), seu efeito nas propriedades funcionais e proteínas do leite e sua aplicação em produtos lácteos. São apresentadas as características da enzima e as principais reações que catalisa, destacando-se o comportamento da transglutaminase em diferentes substratos (caseína e proteínas do soro) e a alteração nas propriedades funcionais das proteínas lácteas após a reação enzimática. A polimerização das proteínas do leite pela transglutaminase parece constituir meio efetivo para o melhoramento das propriedades físicas de produtos lácteos como, queijos, sorvete e iogurte. A reação enzimática catalisada pela transglutaminase confere aos produtos formados características únicas e sua utilização apresenta grande potencial para indústria de alimentos por tratar-se de meio considerado seguro para modificação protéica.
\end{abstract}

PALAVRAS-CHAVE: TRANSGLUTAMINASE; CASEÍNA; $\alpha$-LACTOALBUMINA; $\beta$-LACTOGLOBULINA; PROPRIEDADES FUNCIONAIS.

* Mestre em Ciência dos Alimentos, Departamento de Ciência e Tecnologia de Alimentos, Centro de Ciências Agrárias (CCA), Universidade Federal de Santa Catarina (UFSC), Florianópolis (e-mail: conygauche@yahoo.com.br).

** Bolsista Iniciação Científica PIBIC/CNPq - CAL/CCA/UFSC.

*** Professora, Doutora do Programa de Pós-Graduação em Ciência dos Alimentos (email:bordign@cca.ufsc.br). 


\section{INTRODUÇÃO}

Muitos agentes de polimerização estão disponíveis, mas a utilização de enzimas para a modificação das propriedades funcionais de alimentos via ligações cruzadas de proteínas pode ser mais adequada do que o processo químico. Isto porque são requeridas somente em quantidades catalíticas, há menor probabilidade de produção de compostos tóxicos, sendo percebidas pelos consumidores como mais naturais que os produtos químicos (SINGH, 1991; FAERGEMAND, OTTE e QVIST, 1998).

A transglutaminase (EC 2.3.2.13), enzima capaz de formar ligações inter e intramoleculares em muitas proteínas, catalisa a reação de transferência entre os grupos $\gamma$-carboxiamida dos peptídios ligados aos resíduos de glutamina e várias aminas primárias (ANDO et al., 1989). A polimerização de proteínas catalisadas pela transglutaminase resulta na estabilidade térmica de sistemas e na modificação de propriedades funcionais como, solubilidade, capacidade de hidratação, propriedades reológicas e emulsificantes (KURAISHI, YAMAZAKI e SUSA, 2001).

$O$ efeito da transglutaminase nas proteínas do leite, bastante pesquisado (DICKINSON e YAMAMOTO, 1996; FAERGEMAND, OTTE e QVIST, 1997; RODRIGUEZ-NOGALES, 2006; SHARMA, LORENZEN e QVIST, 2001), resulta na modificação da estrutura das proteínas e de suas propriedades físicas e funcionais.

Esta revisão teve como objetivo destacar as principais características da transglutaminase microbiana independente de cálcio (Streptoverticilium mobaraense), seu efeito nas propriedades funcionais de caseínas ( $\alpha$-lactoalbumina e $\beta$-lactoglobulina), além de sua aplicação em produtos lácteos.

\section{CARACTERÍSTICAS DA ENZIMA TRANSGLUTAMINASE}

A transglutaminase (EC 2.3.2.13), enzima presente naturalmente na maioria dos tecidos animais e fluidos corporais, exerce importante papel na formação da coagulação sanguínea. Identificada por Heinrich Waelsch há mais de 40 anos, a enzima serve para incorporar aminas em proteínas no fígado (LORAND, 2002). A enzima catalisa reação de transferência de grupos acila entre grupos $\gamma$-carboxiamida dos peptídios ligados aos resíduos de glutamina (doador de acila) e os grupos aminos primários de compostos amino (receptor de acila), incluindo os peptídios ligados aos grupos $\varepsilon$-amino dos resíduos de lisina (FOLK e FINLAYSON, 1977; MOTOKI e SEGURO, 1998). Quando os grupos $\varepsilon$-amino dos resíduos de lisina nas proteínas atuam como receptores de grupos acila, ligações $\varepsilon$-( $\gamma$-glutamina)lisina são formadas intra e intermolecularmente. Se não existe amina primária no sistema de reação, a água se torna o receptor de grupos acila e os grupos $\gamma$-carboxiamida dos resíduos de glutamina são desaminados, tornando-se resíduos de ácido glutâmico (ANDO et al., 1989).

A transglutaminase pode modificar as proteínas por meio de incorporação de aminas, ligações cruzadas e desaminação (Figura 1) (MOTOKI e SEGURO, 1998). Essas reações causam alterações nas propriedades funcionais de proteínas vegetais e animais, possibilitando a formação de produtos com melhores propriedades reológicas e sensoriais (NIELSEN, PETERSEN e MOLER, 1995).

A incorporação de ligações intra ou intermoleculares em alimentos protéicos parece viável para o melhoramento das propriedades físicas e de textura de muitos produtos. Existem procedimentos químicos e enzimáticos para introduzir ligações cruzadas covalentes em proteínas. Devido à origem natural da enzima e sua alta especificidade pelo substrato, o procedimento enzimático tornou-se mais aceito por autoridades regulatórias e pelo consumidor (NONAKA et al., 1989).

$O$ aspecto da segurança na ingestão da molécula $\varepsilon$-( $\gamma$-glutamina)lisina formada pela reação catalisada pela transglutaminase está relacionado com a ingestão dessa molécula em alimentos cozidos, já que a transglutaminase está presente na maioria dos tecidos e órgãos de vegetais e animais. Durante o cozimento ou processamento dos alimentos, o aumento da temperatura é freqüentemente lento e as transglutaminases endógenas podem exercer sua atividade enzimática por algum tempo (MOTOKI e SEGURO, 1998). 

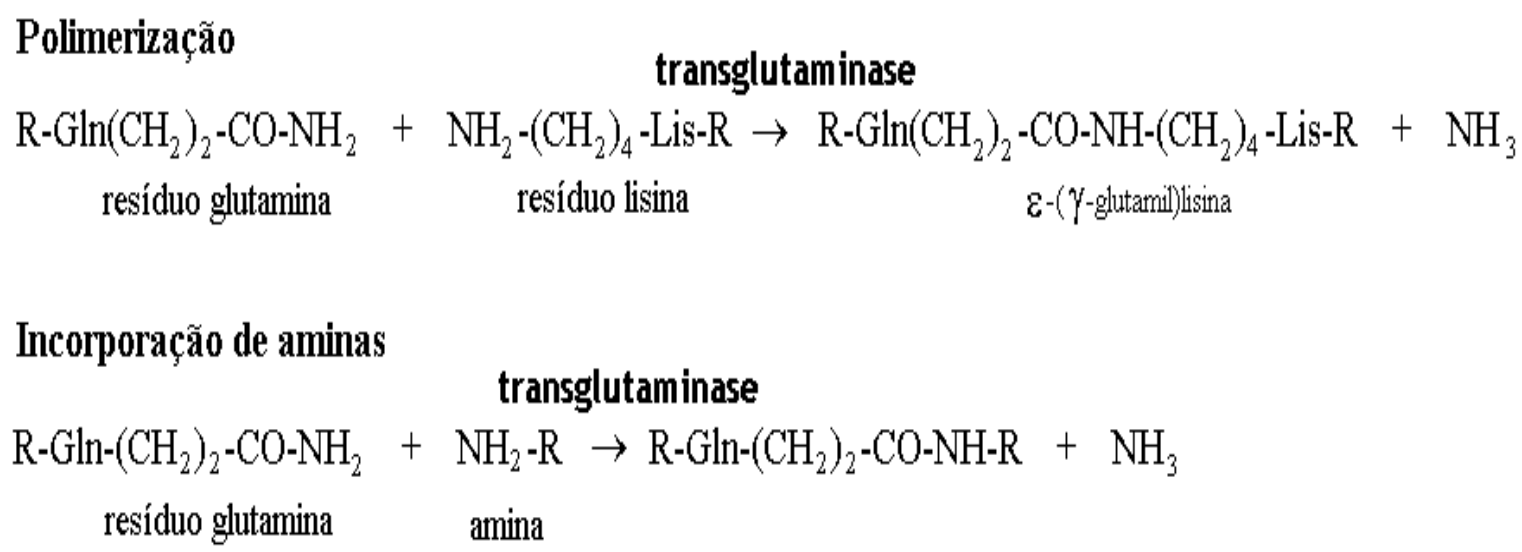

Desaminação

R-Gln- $\left(\mathrm{CH}_{2}\right)_{2}-\mathrm{CO}-\mathrm{NH}_{2} \quad \mathrm{H}_{2} \mathrm{O} \rightarrow$ R-Gln- $\left(\mathrm{CH}_{2}\right)_{2}-\mathrm{CO}-\mathrm{OH}+\mathrm{NH}_{3}$ resíduo glutamina

Fonte: SHARMA, LORENZEN e QVIST, 2001 (adaptado).

A transglutaminase é considerada como Generally Recognized As Safe (GRAS) por cientistas da área (KURAISHI, YAMAZAKI e SUSA, 2001). A legislação brasileira permite a utilização da transglutaminase de origem microbiana (Streptoverticilium mobaraense) na indústria de alimentos em concentração suficiente para o efeito desejado, sem especificar o limite máximo permitido (BRASIL, 2003).

Já na década de 50, a transglutaminase dependente de cálcio mostrava-se capaz de modificar as propriedades da gelatina e outras proteínas pela reação de transferência de grupos acila in vitro (CLARKE et al., 1959). Sua utilidade, no entanto, é limitada pelo alto custo de produção, dependência do cálcio para a atividade (WILCOX e SWAISGOOD, 2002) e pela dificuldade de obtenção (LASTOWKA, MAFFIA e BROWN, 2005). Assim muitas pesquisas são realizadas com o objetivo de encontrar novas fontes viáveis para extração da transglutaminase. Estudos mostram a extração e purificação da transglutaminase a partir de fontes vegetais (KANG e CHO, 1996), de peixes (NOZAWA, MAMEGOSHI e SEKI, 1997; WORRATAO e YOGSAWATDIGUL, 2005) e por recombinação genética (TAGUCHI et al., 2002; DATE et al., 2003). Com a recente disponibilidade da enzima a partir de fonte microbiana, sua aplicação pela indústria de alimentos tornou-se muito pesquisada.

A transglutaminase microbiana de Streptoverticilium mobaraense sp, independente do cálcio, linhagem S-8112 consiste de 331 aminoácidos numa única cadeia polipeptídica e contém resíduo de cisteína com um grupo tiol livre, que é essencial para a atividade enzimática (KANAJl et al., 1993). Essa enzima apresenta massa molar em torno de 40.000 Daltons, valor próximo da metade da transglutaminase derivada de fígado de porco (ANDO et al., 1989). KANAJl et al. (1993) confirmaram a massa molar da transglutaminase microbiana por espectrometria de massa com ionização (ESI), observando valor igual a 37.869,2 $\pm 8,8$ Daltons, próximo ao valor aparente determinado previamente por eletroforese em gel de poliacrilamida por ANDO et al. (1989).

O ponto isoelétrico da transglutaminase microbiana (pl), em torno de 8,9 , difere do $\mathrm{pl}$ da transglutaminase derivada de fígado de porco $(4,5)$ (ANDO et al., 1989). O pH ótimo da transglutaminase 
microbiana gira em torno de 5,0-8,0. Entretanto, a transglutaminase microbiana ainda expressa alguma atividade enzimática em pH 4,0 ou 9,0, sendo considerada estável em ampla faixa de pH (MOTOKI e SEGURO, 1998). A temperatura ótima de atividade enzimática utilizando como substrato hidroxilamina e CBZ-glutamilglicina foi de $50^{\circ} \mathrm{C}$ por 10 minutos (ANDO et al., 1989).

A estabilidade térmica da transglutaminase microbiana foi avaliada por KÜTEMEYER et al. (2005) mediante adição de diferentes sais em várias concentrações. A adição de íons monovalentes $(\mathrm{NaCl}, \mathrm{KCl})$ aumentou a atividade enzimática e a estabilidade térmica da transglutaminase, enquanto íons bivalentes evidenciaram pouca influência $\left(\mathrm{MgCl}_{2}\right)$ ou reduziram a atividade enzimática e a estabilidade térmica $\left(\mathrm{CaCl}_{2}\right)$.

A estabilidade térmica de proteínas miofibrilares aumenta com a adição da transglutaminase (AKTAS e KILIÇ, 2005), assim como a capacidade e a força do gel de surimi são melhoradas pelo tratamento enzimático (DONDERO et al., 2006). A transglutaminase adicionada em farinha de trigo permite a formação de pães com maior volume e consistência, além de menor acidez (COLLAR, BOLLAÍN e ANGIOLONI, 2005). O tratamento enzimático do leite afeta sua estabilidade térmica (O'SULLIVAN, KELLY e FOX, 2002) e o iogurte produzido com o leite pré-tratado com transglutaminase apresenta menor sinérese e maior força do gel (LORENZEN et al., 2002). Muitas aplicações são propostas para a transglutaminase como ingrediente no processamento de alimentos por ser considerada como meio seguro de modificação de proteínas e por conferir características únicas aos alimentos.

\section{MODIFICAÇÃO DAS PROTEÍNAS DO LEITE POR TRANSGLUTAMINASE - ALTERAÇÃO DAS PROPRIEDADES FUNCIONAIS}

Indústrias alimentícias de todo o mundo estão em busca do desenvolvimento de ingredientes ou produtos lácteos com novas características físicas e funcionais. Um dos objetivos é a alteração das propriedades dos produtos lácteos pela modificação das proteínas do leite utilizando a transglutaminase (RODRIGUEZ-NOGALES, 2006; SHARMA, LORENZEN e QVIST, 2001). Dentre as proteínas do leite destacam-se as caseínas (COZZOLINO et al., 2003; O'CONNELL e KRUIF, 2003), consideradas bons substratos para a transglutaminase. A incubação de soluções de $\beta$ - e $\kappa$ - caseínas com transglutaminase leva a formação de ligações intramoleculares nas micelas de caseína, sendo o efeito das ligações cruzadas mais pronunciado na K-caseína (KRUIF et al., 2002). A maior reatividade das K-caseínas deve-se a sua localização na superfície da micela, além disso os macropeptídios das א-caseínas são muito acessíveis ao ataque da transglutaminase (RODRIGUEZ-NOGALES, 2005).

SHARMA, LORENZEN e QVIST (2001) estudaram o efeito da transglutaminase após reação enzimática com as proteínas de leite em pó desnatado reconstituído. Constataram em perfil de eletroforese SDS-PAGE que o tempo de reação de 30 minutos diminuiu a intensidade das bandas de caseína, no entanto, após o aquecimento do leite verificaram considerável diminuição na intensidade de caseína (mais que 50\%) durante os primeiros 30 minutos de reação. Tempo adicional de reação causou maior diminuição na intensidade das bandas de caseína. Tanto a $\beta$-caseína como a k-caseína mostraram-se mais susceptíveis à reação enzimática do que a $\alpha_{\mathrm{s}}$-caseína no meio natural da micela de caseína, sendo que a k-caseína evidenciou maior reatividade sem o tratamento térmico. O mesmo comportamento foi encontrado no tratamento do leite de cabra e de ovelha com transglutaminase (RODRIGUEZ-NOGALES, 2005; RODRIGUEZNOGALES, 2006). A polimerização das formas monoméricas das proteínas aumenta após o tratamento térmico do leite a $85^{\circ} \mathrm{C}$ por 15 minutos, sendo menos intensa para a $\alpha_{s}$-caseína. O pré-aquecimento do leite causa a desnaturação das proteínas do soro e sua interação com as micelas de caseína, aumentando a susceptibilidade das proteínas à reação com a transglutaminase (SHARMA, LORENZEN e QVIST, 2001). Em geral, o aumento progressivo da temperatura desorganiza o sistema proteína-água quebrando as ligações de hidrogênio que estabilizam a estrutura protéica. Isso causa o desdobramento e provoca a interação proteína-proteína, aproximando as proteínas do sítio ativo da transglutaminase e levando à subseqüente formação dos polímeros (NIEUWENHUIZEN et al., 2003). 
A forte reatividade da $\kappa$-caseína já foi esclarecida pela sua posição externa na micela de caseína. A estrutura da micela permite o acesso da transglutaminase à $\beta$-caseína, mais acessível que a $\alpha_{s}$-caseína (SHARMA, LORENZEN e QVIST, 2001). Enquanto a $\beta$-caseína apresenta estrutura aberta, desordenada e flexível, a $\alpha_{s}$-caseína forma estrutura fechada, dificultando a ação da transglutaminase (RODRIGUEZ-NOGALES, 2005).

Os resíduos de glutamina localizados na região $\mathrm{N}$-terminal (hidrofílica) da $\beta$-caseína são preferencialmente modificados pela transglutaminase, sendo a especificidade à região $\mathrm{N}$-terminal dos resíduos de glutamina da $\beta$-caseína consequência da exposição ao solvente ou da carga dos aminoácidos adjacentes a glutamina. Quando incubada a $35^{\circ} \mathrm{C}$ por 100 minutos, a região $\mathrm{N}$-terminal hidrofílica da $\beta$-caseína torna-se disponível no solvente aquoso, ocorrendo polimerização pela transglutaminase (O'CONNEL e KRUIF, 2003). As alterações associadas à transglutaminase nas propriedades físico-químicas da $\beta$-caseína podem representar aumento na hidrofobicidade da molécula e estabilidade do cálcio das micelas de $\beta$-caseína tratadas com transglutaminase.

A formação de gel induzido pela transglutaminase é possível pela polimerização enzimática de micelas de caseína (SCHORSCH, CARRIE e NORTON, 2000a). O gel de proteínas do leite forma-se tradicionalmente pelo tratamento de caseína com ácido ou enzima proteolítica (renina), ou por desnaturação térmica das proteínas do soro. Outra alternativa seria a polimerização enzimática das moléculas de proteína, produzindo uma rede de ligações covalentes. Devido às diferentes ligações cruzadas formadas, espera-se que a rede protéica apresente propriedades reológicas completamente diferentes do gel de proteínas de leite convencional (DICKINSON e YAMAMOTO, 1996).

As caseínas nativas, altamente hidratadas e de grande volume, são encontradas no leite ( $\mathrm{pH}$ $6,8)$ como micelas coloidais em associação com fosfato de cálcio. Quando a transglutaminase é adicionada ao leite não ocorre a formação de gel, sugerindo que tal incapacidade seja devida à repulsão eletrostática e/ou estérica entre as moléculas de $\kappa$-caseína na superfície. Espera-se o efeito da transglutaminase quando a estabilização eletrostática e/ou estérica das proteínas é removida como, por exemplo, pela acidificação do leite (SCHORSCH, CARRIE e NORTON, 2000b).

Emulsões elaboradas pela polimerização de soluções de caseinato com transglutaminase em concentrações protéicas superiores a $0,2 \%$ são finas e pouco estáveis à coalescência e floculação durante a estocagem (FAERGEMAND, OTTE e QVIST, 1998). Moléculas protéicas polimerizadas não são absorvidas na interface óleo-água, diminuindo a estabilidade da emulsão pela menor superfície de contato. O tratamento com transglutaminase em soluções com alta concentração protéica aumenta o tamanho médio das gotas, o qual pode ser atribuído à floculação causada pela polimerização covalente envolvendo moléculas de proteínas (FAERGEMAND et al., 1999).

A estabilidade térmica de soluções de caseinato de sódio modificadas pela transglutaminase leva à agregação das proteínas em temperaturas superiores em relação às soluções controle. A turbidez da solução de caseína permanece inalterada até a temperatura de $56^{\circ} \mathrm{C}$, aumentando até o máximo em $85^{\circ} \mathrm{C}$. Nas soluções tratadas enzimaticamente, a turbidez permanece inalterada até a temperatura de $80^{\circ} \mathrm{C}$. Tratamentos mais longos (18 horas) aumentam a estabilidade até $95^{\circ} \mathrm{C}$ (MUGURAMA et al., 2003).

A viscosidade tempo-dependente de filmes de $\alpha_{\mathrm{s}}$-caseína, $\beta$-caseína e caseinato de sódio polimerizados por transglutaminase imediatamente após a formação dos filmes aumenta a viscosidade na interface em até 100 vezes. O aumento da viscosidade da superfície da $\beta$-caseína é proporcional ao da viscosidade do filme de caseinato de sódio, enquanto a viscosidade do filme de $\alpha_{\mathrm{s}}$-caseína eleva-se lentamente. A taxa similar de aumento da viscosidade para a $\beta$-caseína em relação ao caseinato de sódio pode ser devido ao fato da $\beta$-caseína absorver mais rápido na interface óleo-água, além disso a $\beta$-caseína é melhor substrato para a transglutaminase do que a $\alpha_{s}$-caseína (FAERGEMAND et al., 1999).

As proteínas do soro de leite, $\beta$-lactoglobulina e $\alpha$-lactoalbumina, tendem a formar reações cruzadas menos efetivas com a transglutaminase por apresentarem estrutura globular. Estudos mostram que a adição de agentes redutores ao sistema facilita a reação das proteínas com a transglutaminase 
por manter o sítio ativo sulfidril no estado reduzido, aumentando o acesso da enzima aos grupos $\mathrm{NH}_{2}$ (WILCOX e SWAISGOOD, 2002; KURAISHI, YAMAZAKI e SUSA, 2001). Estudo sobre a polimerização de proteínas do soro por transglutaminase dependente de cálcio, realizado em 1990, mostrou a polimerização protéica das proteínas globulares do soro. A polimerização das proteínas de soro em pó por transglutamianse, na concentração protéica de 12\%, só foi possível após o tratamento das soluções com DTT (agente redutor), sendo máxima em pH 7,5 (ABOUMAHMOUD e SAVELLO, 1990).

Após a incubação de proteínas isoladas de soro com transglutaminase por 60 minutos ocorre reação cruzada da $\alpha$-lactoalbumina com a enzima, a qual é mais fraca com a $\beta$-lactoglobulina (FAERGEMAND, OTTE e QVIST, 1997). Esses dados sugerem que a $\alpha$-lactoalbumina apresenta resíduos de glutamina e lisina disponíveis para a reação cruzada com a transglutaminase, enquanto esses resíduos estão menos disponíveis à reação na $\beta$-lactoglobulina. Após a adição de DTT, reduzindo as pontes dissulfeto que estabilizam a $\alpha$-lactoalbumina (4 S-S) e a $\beta$-lactoglobulina ( $2 \mathrm{~S}$-S), a reatividade da transglutaminase aumenta com as duas proteínas. A $\alpha$-lactoalbumina reage imediatamente, mas a reação com a $\beta$-lactoglobulina depende da dose de proteína utilizada e da concentração protéica da solução (FAERGEMAND, OTTE e QVIST, 1997).

A utilização de concentrado industrial de $\alpha$-lactoalbumina, transglutaminase, DTT (agente redutor) e SDS para a reação enzimática levam a consideráveis ligações cruzadas observadas em gel de poliacrilamida (SDS-PAGE) entre as proteínas. Essas ocorrem com ou sem adição de agente redutor à solução protéica (SHARMA, ZAKORA e QVIST, 2002a). A reação da $\alpha$-lactoalbumina com transglutaminase na presença de cálcio e DTT leva a formação de polímeros com massa molar de 600.000 Daltons em 15 minutos a partir de seus monômeros que apresentam massa molar de 14.200 Daltons (MATSUMURA, LEE e MORI, 2000). Os grandes agregados formados devido à polimerização da $\alpha$-lactoalbumina pela transglutaminase são capazes de formar filme coeso em curto espaço de tempo ( 1 hora). Agregados maiores absorvidos na interface óleo-água, razoavelmente rígidos e difíceis à propagação, são tão incapazes de aumentar a força do filme interfacial quanto a proteína não polimerizada enzimaticamente (SHARMA, ZAKORA e QVIST, 2002b).

A presença de ligações $\varepsilon$-( $\gamma$-glutamina) lisina catalisadas pela transglutaminase em soluções de isolado protéico de soro de leite, submetidas à desnaturação por DTT, impede a formação de associações hidrofóbicas entre as proteínas e diminui a viscosidade das soluções (EISSA e KHAN, 2006). O DTT quebra as ligações dissulfeto, impossibilitando a formação de associações hidrofóbicas significativas. A transglutaminase produz ligações cruzadas que reduzem a exposição das moléculas hidrofóbicas mediante impedimento estérico e a formação de moléculas compactas, o que afeta as interações físicas entre as proteínas e diminui a viscosidade da solução.

A susceptibilidade das proteínas de leite desnatado à reação cruzada com transglutaminase, avaliada por eletroforese capilar após seu aquecimento a $85^{\circ} \mathrm{C}$ por 15 minutos, demonstra a polimerização enzimática das proteínas do soro pela diminuição da área do pico obtido pela eletroforese. A $\alpha$ lactoalbumina reage tanto no leite aquecido como no leite que não sofreu o processo de pré-aquecimento. A $\beta$-lactoglobulina reage com a transglutaminase somente quando o leite é submetido ao tratamento térmico (SHARMA, LORENZEN e QVIST, 2001).

O tratamento do leite de ovelha com transglutaminase mostra que a reatividade das proteínas do soro aumenta com o aquecimento do leite a $85^{\circ} \mathrm{C}$ por 15 minutos. Considerável redução nas concentrações de $\alpha$-lactoalbumina e $\beta$-lactoglobulina foi observada em eletroforese capilar, sendo mais notável para a $\beta$-lactoglobulina (RODRIGUEZ-NOGALES, 2005). Quanto à reatividade das proteínas do soro de leite de cabra, a eletroforese capilar mostrou redução significativa do pico de $\alpha$-lactoalbumina após a reação enzimática sem tratamento térmico (RODRIGUEZ-NOGALES, 2006).

$\mathrm{O}$ efeito do $\mathrm{pH}$ no tratamento enzimático de proteínas isoladas do soro de leite foi avaliado pela incubação das amostras a $50^{\circ} \mathrm{C}$ por 5 horas, com $100 \mathrm{U}$ de transglutaminase/g de proteína em $\mathrm{pH} 6$, 7 e 8. A SDS-PAGE mostrou banda de $\beta$-lactoglobulina inalterada após o tratamento enzimático em valores de $\mathrm{pH} 6$ e 7 , que se torna muito fraca em pH 8. No entanto, a $\alpha$-lactoalbumina reage com a transglutaminase em todos os valores de $\mathrm{pH}$ indicando que pode ser rapidamente polimerizada pela 
transglutaminase em diferentes valores de $\mathrm{pH}$. Já a $\beta$-lactoglobulina requer condições do meio fracamente alcalinas (EISSA, BISRAM e KHAN, 2004).

As modificações nos resíduos de glutamina e lisina da $\alpha$-lactoalbumina após a reação enzimática com transglutaminase microbiana ocorre em no máximo cinco lisinas e cinco glutaminas, dependendo da temperatura, $\mathrm{pH}$, presença e ausência de cálcio. Cinco glutaminas (39, 43, 54, 65 e 117) e cinco lisinas $(5,13,16,108$ e 114) estão disponíveis para modificação por transglutaminase na apo- $\alpha$ lactoalbumina, enquanto que nenhuma glutamina e quatro lisinas $(13,16,108,114)$ estão disponíveis na holo- $\alpha$-lactoalbumina (NIEUWENHUIZEN et al., 2003). A polimerização das proteínas pela transglutaminase é afetada pela disponibilidade dos resíduos de glutamina e lisina na superfície da proteína, como também pode ser potencialmente influenciada pela compatibilidade termodinâmica da mistura de substratos protéicos pelo centro ativo da enzima (HAN e DAMODARAN, 1996).

Quando a mistura de $\beta$-caseína e $\beta$-lactoglobulina é incubada com transglutaminase a $2 \mathrm{U} / \mathrm{g}$ de proteína, a concentração de $\beta$-caseína monomérica diminui e várias bandas de polímeros com alto peso molecular aparecem em SDS-PAGE. Aintensidade dos monômeros de $\beta$-lactoglobulina permanece a mesma nas amostras tratadas, indicando que a $\beta$-lactoglobulina não faz parte da reação de polimerização induzida pela transglutaminase. No entanto, a $\beta$-lactoglobulina tratada enzimaticamente com transglutaminase isoladamente apresenta diminuição significativa nas bandas de seus monômeros (HAN e DAMODARAN, 1996). Esses resultados indicam que num sistema protéico simples a $\beta$ lactoglobulina atua como substrato para a transglutaminase, enquanto que na presença de $\beta$-caseína não é utilizada pela enzima. $\beta$-Caseína e $\beta$-lactoglobulina não se aproximam simultaneamente do centro ativo da enzima, fenômeno que deve estar relacionado em parte com a incompatibilidade termodinâmica da mistura dessas duas proteínas pelo centro ativo da transglutaminase.

O aumento na força iônica da solução diminui a efetividade da reação de polimerização das cadeias de proteínas do soro. Altas concentrações de sal favorecem o aparecimento de bandas mais escuras de $\alpha$-lactoalbumina e $\beta$-lactoglobulina, indicando maior concentração de frações protéicas não-polimerizadas pela transglutaminase (EISSA, BISRAM e KHAN, 2004). Em forças iônicas altas ocorrem interações eletrostáticas entre as cadeias de proteínas, cujas interações são selecionadas e as cadeias entram em "colapso". Esse colapso previne a alteração da estrutura protéica da $\alpha$ lactoalbumina e $\beta$-lactoglobulina, mascarando os grupos catalíticos (glutamina e lisina) requeridos para a ação da enzima.

O efeito da polimerização da $\alpha$-lactoalbumina pela transglutaminase, avaliada antes e após o processo de emulsificação da solução protéica, confere baixa estabilidade à emulsão controle (sem transglutaminase). Isso ocorre, provavelmente devido à estrutura secundária altamente ordenada da $\alpha$ lactoalbumina que impede o desdobramento na interface óleo-água. A polimerização das proteínas antes da emulsificação diminui a estabilidade da emulsão pela quantidade reduzida de proteína absorvida na superfície. A polimerização das proteínas após o processo de emulsificação leva a formação de emulsões mais estáveis (SHARMA, ZAKORA e QVIST, 2002b). Emulsões protéicas de $\beta$-lactoglobulina, tratadas com transglutaminase após o processo de emulsificação, apresentam menor efetividade emulsificante pelo tratamento enzimático. Como a polimerização da $\beta$-lactoglobulina reduz a flexibilidade molecular da proteína globular, sua efetividade em envolver a nova interface óleo-água para formar camada mais estável é menor (DICKINSON e YAMAMOTO, 1996).

A alteração correspondente ao módulo elástico e viscoso, após adição de glucono- $\delta$-lactona (GDL) às soluções protéicas na elaboração de géis ácidos de proteínas do soro polimerizadas por transglutaminase, resulta em maior módulo elástico (G') para a amostra tratada enzimaticamente em relação a amostra controle (não-tratada). Uma vez que G' está relacionado ao grau de polimerização, isso sugere a presença de ligações cruzadas adicionais nas amostras tratadas com transglutaminase. A presença da polimerização protéica (ligações $\varepsilon$ - $(\gamma$-glutamina)lisina) fortalece a rede estrutural e confere aumento de $50 \%$ na força de quebra do gel formado (EISSA, BISRAM e KHAN, 2004).

A estabilidade térmica do leite é sensível a vários fatores de sua composição $(\mathrm{pH}$, sais e proteínas do leite) e processos de tratamento (pré-aquecimento, concentração, homogeinização) que 
podem causar coagulação parcial ou completa durante o processamento, ou gelificação durante o armazenamento (SINGH e CREAMER, 1992 apud O'SULLIVAN, KELLY e FOX, 2002). O tratamento de proteínas com transglutaminase pode modificar suas propriedades de hidratação, gelificação, reologia, emulsificação e estabilidade térmica (ANEMA et al., 2005; PIETRASIK, 2003; FAERGEMAND, OTTE e QVIST, 1998), mediante incorporação de aminas, ligações cruzadas e reações de desaminação (MOTOKI e SEGURO, 1998).

O tratamento do leite com transglutaminase afeta sua estabilidade térmica. No leite cru a formação de ligações cruzadas entre as caseínas individuais é responsável por prevenir a dissociação da א-caseína das micelas em valores de pH na região de mínima estabilidade. Em leites pré-aquecidos, antes da incubação com transglutaminase, a desnaturação das proteínas do soro pode permitir a formação de ligações cruzadas pela transglutaminase entre as proteínas desnaturadas do soro e as caseínas individuais que (em combinação com as ligações cruzadas das caseínas) contribuem para o melhoramento da estabilidade térmica do leite em pH > 6,5 (O'SULLIVAN, KELLY e FOX, 2002).

O tratamento enzimático com transglutaminase para gerar géis ácidos a partir de leite produz gel com maior rigidez e tensão de quebra e menor permeabilidade que o leite não-tratado, indicando que a introdução de ligações covalentes cruzadas na rede de proteínas modifica marcadamente a estrutura do gel ácido (ANEMA et al., 2005).

\section{TRANSGLUTAMINASE EM PRODUTOS LÁCTEOS}

A incorporação de até $2 \mathrm{~g}$ de proteínas do soro de leite ao coágulo do queijo pela adição da transglutaminase não implica em alteração de textura e deformabilidade do produto final (COZZOLINO et al., 2003).

Sorvete tratado com transglutaminase é mais liso e mais fácil de "bolear", especialmente no caso de sorvetes sem açúcar e baixa caloria, cuja textura em forma de gelo danifica freqüentemente a qualidade do produto (KURAISHI, YAMAZAKI e SUSA, 2001). Quando formulações de sorvete são tratadas com transglutaminase antes da pasteurização da mistura e do congelamento subseqüente, 0 perfil de derretimento do sorvete é variavelmente afetado, dependendo do tempo de incubação e da concentração enzimática (O’KENNEDY, 2003).

$\mathrm{O}$ efeito da inativação térmica $\left(30^{\circ} \mathrm{C} / 1 \mathrm{~min}\right)$ e da incubação da transglutaminase, simultaneamente ao processo de fermentação (não-inativada) sugere que o aumento da viscosidade e a redução da sinérese dos iogurtes são mais efetivos quando a transglutaminase não é inativada (LORENZEN et al., 2002).

O nível de oligomerização das moléculas de caseína no processamento de iogurte após a adição de transglutaminase é de $10,9 \%$ no produto preparado da forma tradicional (sem enzima) e de $25,8 \%$ com o tratamento enzimático $(3 \mathrm{U} / \mathrm{g}$ ). A polimerização intermolecular das caseínas induzidas por transglutaminase melhora a gelificação, produzindo mudanças significativas nas propriedades funcionais das proteínas do leite (LAUBER, HENLE e KLOSTERMEYER, 2000).

O pré-tratamento do leite com transglutaminase microbiana (2 e $4 \mathrm{U} / \mathrm{g}$ ) aumenta significativamente $(p<0,05)$ a viscosidade e diminui a sinérese de amostras de iogurte de cabra (FARNSWORTH et al., 2006). O efeito do tratamento com a enzima é mais significante no melhoramento da viscosidade do iogurte comparado ao método do aumento do conteúdo de sólidos totais do leite. $O$ tratamento enzimático com transglutaminase leva à polimerização das proteínas do leite, principalmente das caseínas, resultando no aumento da força do gel do iogurte. A viscosidade dos iogurtes tratados com 2,5 U de transglutaminase aumentou cerca de 3,5 vezes quando comparada ao iogurte nãoadicionado da enzima (amostra controle). Resultados similares foram encontrados em iogurtes elaborados a partir de leite bovino, não havendo diferença significativa no conteúdo de nutrientes básicos entre as amostras controle e testes.

O enriquecimento da matéria seca (sólidos totais) e/ou conteúdo protéico, como também a 
adição de hidrocolóides (como gelatina e amido), são maneiras comuns de evitar problemas como a sinérese no processamento de iogurte (LORENZEN et al., 2002). A polimerização das cadeias de proteínas do leite para a estabilização da rede tridimensional do iogurte surge como nova tecnologia na prevenção de problemas comuns no processamento de produtos lácteos.

\section{CONCLUSÃo}

A polimerização das proteínas do leite pela transglutaminase parece constituir meio efetivo para o melhoramento das propriedades físicas de produtos lácteos como, queijos, sorvete e iogurte.

A reação enzimática catalisada pela transglutaminase confere aos produtos formados características únicas e sua utilização apresenta grande potencial para indústria de alimentos por tratar-se de meio considerado seguro para modificação protéica.

\section{ABSTRACT \\ CROSSLINKING OF MILK PROTEINS BY TRANSGLUTAMINASE: FUNCTIONAL PROPERTIES MODIFICATIONS AND USE IN DAIRY PRODUCTS}

This paper presents a literature review of the main characteristics of a microbial transglutaminase isolated from Streptoverticilium mobaraense, its effects on the functional properties of milk proteins and applications on dairy products. It was demonstrated the principal characteristic of the enzyme and the reactions catalyzed by it, having as outstanding characteristic its behavior in different substrates (caseins and whey proteins) and changes on functional properties of milk proteins after enzymatic reaction. The crosslinking of milk proteins through transglutaminase appears to constitute effective mean to the improvement of physical milk properties of products such as cheeses, milks, ice cream and yogurt. The enzymatic reaction catalyzed by transglutaminase attributes to the formed products unique characteristics and its use has great potential for the food industry. That is because it is considered to be a safe mean of protein modification.

KEY-WORDS: TRANSGLUTAMINASE; CASEIN; $\alpha$-LACTALBUMIN; $\beta$-LACTOGLOBULIN; FUNCTIONAL PROPERTIES.

\section{REFERÊNCIAS}

1 ABOUMAHMOUD, R.; SAVELLO, P. Crosslinking of whey protein by transglutaminase. Journal of Dairy Science, v. 73, p. 256-263, 1990.

2 AKTAS, N.; KILIÇ, B. Effect of microbial transglutaminase on thermal and eletrophoretic properties of ground beef. Lebensmittel - Wissenschaft und - Technologie, v. 38, p. 815-819, 2005.

3 ANDO, H.; ADACHI, M.; UMEDA, K.; MATSURA, A.; NONAKA, M.; UCHIO, R.; TANAKA, H.; MOTOKI, M. Purification and characteristics of a novel transglutaminase derived from microorganisms. Agricultural and Biological Chemistry, v.53, n.10, p. 2613-2617,1989.

4 ANEMA, S.G.; LAUBER, S.; LEE, S.K.; HENLE, T.; KLOSTERMEYER, H. Rheological properties of acid gels prepared from pressure and transglutaminase treated skim milk. Food Hydrocolloids, v.19, p. 879887, 2005.

5 BRASIL. Agência Nacional de Vigilância Sanitária. Resolução RDC no 348, de 02 de dezembro de 2003. Aprova de forma complementar ao Anexo da Resolução CNNPA nº 24 de 1976, a utilização de enzimas na indústria de alimentos. Diário Oficial da República Federativa [do] Brasil, Brasília, 03 de dezembro de 2003.

6 CLARKE, D.D.; MYCEK, M.J.; NEIDLE, A.; WAELSCH, H. The incorporation of amines into protein. Archives of Biochemistry and Biophysics, v. 79, p. 338-354, 1959.

7 COLLAR, C.; BOLLAÍN, C.; ANGIOLONI, A. Significance of microbial transglutaminase on the sensorial, mechanical and crumb grain pattern of enzyme supplemented fresh pan breads. Journal of Food Engineering, v. 70, p. 479-488, 2005. 
8 COZZOLINO, A.; PIERRO, P.D.; MARINIELLO, L.; SORRENTINO, A.; MASI, P.; PORTA, R. Incorporation of whey proteins into cheese curd by using transglutaminase. Biotechnololy and Applied Biochemistry, $v$. 38, p. 289-295, 2003.

9 DATE, M.; YOKOYAMA, K.; UMEZAWAY, Y.; MATSUI, H.; KIKUCHI, Y. Production of native-type Streptoverticilium mobaraense transglutaminase in Corynebacterium glutamicum. Applied and Environmental Microbiology, v. 69, n. 5, p. 3011-3014, 2003.

10 DICKINSON, E.; YAMAMOTO, Y. Rheology of milk protein gels and protein-stabilized emulsion gels crosslinked with transglutaminase. Journal of Agriculture and Food Chemistry, v. 44, p. 1371-1377, 1996.

11 DONDERO, M.; FIGUEROA, V.; MORALES, X.; CUROTTO, E. Transglutaminase effects on gelation capacity of thermally induced beef protein gels. Food Chemistry, v. 99, p. 546-554, 2006.

12 EISSA, A.S.; BISRAM, S.; KHAN, S.A. Polymerization and gelation of whey protein isolates at low pH using transglutaminase enzyme. Journal of Agriculture and Food Chemistry, v. 52, p. 4456-4464, 2004.

13 EISSA, A.S.; KHAN, S.A. Modulation of hydrophobic interactions in denatured whey proteins by transglutaminase enzyme. Food Hydrocolloids, v. 20, p. 543-547, 2006.

14 FAERGEMAND, M.; OTTE, J.; QVIST, K.B. Enzymatic cross-linking of whey proteins by a Ca ${ }^{2+}$-independent microbial transglutaminase from Streptomyces lydicus. Food Hydrocolloids, v. 11, n. 1, p. 19-25, 1997.

15 FAERGEMAND, M.; OTTE, J.; QVIST, K.B. Emulsifying properties of milk proteins cross-linked with microbial transglutaminase. International Dairy Journal, v. 8, p. 715-723, 1998.

16 FAERGEMAND, M.; MURRAY, B.S.; DICKINSON, E.; QVIST, K.B. Cross-linking of adsorbed casein films with transglutaminase. International Dairy Journal, v. 9, p. 343-346, 1999.

17 FARNSWORTH, J.P.; LI, J.; HENDRICKS, G.M.; GUO, M.R. Effects of transglutaminase treatment on functional properties and probiotic cultures survivability of goat milk yogurt. Small Ruminant Research, v. 65, p. 113-121, 2006.

18 FOLK, J.E.; FINLAYSON, J.S. The $\varepsilon$-( $\gamma$-glutamyl)lysine cross-link and the catalytic role of transglutaminase. Advances in Protein Chemistry, v. 31, p. 1-133, 1977.

19 HAN, X-D.; DAMODARAN, S. Thermodynamic compatibility of substrate proteins affects their crosslinking by transglutaminase. Journal of Agriculture and Food Chemistry, v. 44, p. 1211-1217, 1996.

20 KANAJI, T.; OZAKI, H.; TAKAO, T.; KAWAJIRI, H.; IDE, H.; MOTOKI, M.; SHIMONISHI, Y. Primary structure of microbial transglutaminase from Streptoverticilium sp. Strain S-8112. The Journal of Biological Chemistry, v. 268, n. 16, p. 11565-11572, 1993.

21 KANG, H.; CHO, Y.D. Purification and properties of transglutaminase from soybean (Glycine max) leaves. Biochemical and Biophysical Research Communications, v. 223, p. 288-292, 1996.

22 KRUIF, C.G.; TUINIER, R.; HOLT, C.; TIMMINS, P.A.; ROLLEMA, H.S. Physicochemical study of $\beta$ - and $\kappa$-casein dispersions and the effect of cross-linking by transglutaminase. Langmuir, v. 18, p. 4885-4891, 2002.

23 KURAISHI, C.; YAMAZAKI, K.; SUSA, Y. Transglutaminase: its utilization in the food industry. Food Reviews International, v. 17, n. 2, p. 221-246, 2001.

24 KÜTEMEYER, C.; FROECK, M.; WERLEIN, H.D.; WATKINSON, B.M. The influence of salts and temperature on enzymatic activity of microbial transglutaminase. Food Control, v. 16, p. 735-737, 2005.

25 LASTOWKA, A.; MAFFIA, G.F.; BROWN, E.M. A comparison of chemical, physical and enzimatic crosslinking of bovine type I collagen fibrils. JALCA, v. 100, p. 196-202, 2005.

26 LAUBER, S.; HENLE, T.; KLOSTERMEYER, H. Relationship between the crosslinking of caseins by transglutaminase and the gel strength of yogurt. European Food Research and Technolology, v. 210, p. 305-309, 2000.

27 LORAND, L. Transglutaminase: remembering Heinrich Waelsch. Neurochemistry International, v. 40, p. 7-12, 2002. 
28 LORENZEN, P.C.; NEVE, H.; MAUTNER, A.; SCHLIMME, E. Effect of enzymatic cross-linking of milk proteins on functional properties of set-style yoghurt. International Journal of Dairy Technology, v. 55, n. 3, p. 152-157, 2002.

29 MATSUMURA, Y.; LEE, D-S.; MORI, T. Molecular weight distributions of $\alpha$-lactalbumin polymers formed by mammalian and microbial transglutaminases. Food Hydrocolloids, v. 14, p. 49-59, 2000.

30 MOTOKI, M.; SEGURO, K. Transglutaminase and its use for food processing. Trends in Food Science \& Technology, v. 9, p. 204-210, 1998.

31 MUGURAMA, M.; TSURUOKA, K.; KATAMAYMA, K.; ERWANTO, Y.; KAWAHARA, S.; YAMAUCHI, K.; SATHE, S.K.; SOEDA, T. Soybean and milk proteins modified by transglutaminase improves chicken sausage texture even at reduced levels of phopshate. Meat Science, v. 63, p. 191-197, 2003.

32 NIELSEN, G.S; PETERSEN, B.R.; MOLLER, A.J. Impact of salt, phosphate and temperature on the effect of a transglutaminase (F XIIIA) on the texture of restructured meat. Meat Science, v. 41, n. 3, p. 293-299, 1995.

33 NIEUWENHUIZEN, W.F.; DEKKER, H.L.; KONING, L.J.; GRÖNEVELD, T.; KOSTER, C.G.; JONG, G.A.H. Modification of glutamine and lysine residues in holo and apo $\alpha$-lactalbumin with microbial transglutaminase. Journal of Agricultural and Food Chemistry, v. 51, p. 7132-7139, 2003.

34 NONAKA, M.; TANAKA, H.; OKIYAMA, A.; MOTOKI, M.; ANDO, H.; UMEDA, K.; MATSURA, A. Polymerization of several proteins by $\mathrm{Ca}^{2+}$ - independent transglutaminase derived from microorganisms. Agricultural and Biological Chemistry, v. 53, n. 10, p. 2619-2623, 1989.

35 NOZAWA, H.; MAMEGOSHI, S.; SEKI, N. Parcial purification and characterization of six transglutaminases from ordinary muscles of various fishes and marine invertebrates. Comparative Biochemistry and Physiology Part B - Biochemistry and Molecular Biology, v. 142, n. 3, p. 302-307, 1997.

36 O'CONNEL, J.E.; KRUIF, C.G. $\beta$-Casein micelles: cross-linking with transglutaminase. Colloids and Surfaces A - Physicochemical and Engineering Aspects, v. 216, p. 75-81, 2003.

37 O'KENNEDY, B. The use of transglutaminase in food products. The Irish Scientist - Year Book, 2003. Disponível em: http://www.irishscientist.ie/2003/contents.asp? contentxml=03p38b. xml \& contentxsl=is03page36.xs/ Acesso: em 16/05/2006.

38 O'SULLIVAN, M.M.; KELLY, A.L.; FOX, P.F. Effect of transglutaminase on the heat stability of milk: a possible mechanism. Journal of Dairy Science, v. 85, n. 1, p. 1-7, 2002.

39 PIETRASIK, Z. Binding and textural properties of beef gels processed with $\kappa$-carragen, egg albumin and microbial transglutaminase. Meat Science, v. 63, p. 317-324, 2003.

40 RODRIGUEZ-NOGALES, J.M. Enzymatic cross-linking of ewe's milk proteins by transglutaminase. European Food Research and Technolology, v. 221, p. 692-699, 2005.

41 RODRIGUEZ-NOGALES, J.M. Effect of preheat treatment on the transglutaminase-catalysed crosslinking of goat milk proteins. Process Biochemistry, v. 41, p. 430-437, 2006.

42 SCHORSCH, C.; CARRIE, H.; NORTON, I.T. Cross-linking casein micelles by a microbial transglutaminase conditions for formation of transglutaminase-induced gels. International Dairy Journal, v. 10, p. 519-528, 2000a.

43 SCHORSCH, C.; CARRIE, H.; NORTON, I.T. Cross-linking casein micelles by a microbial transglutaminase: influence of cross-links in acid-induced gelation. International Dairy Journal, v. 10, p. 529-539, 2000b.

44 SHARMA, R.; LORENZEN, P.C.; QVIST, K.B. Influence of transglutaminase treatment of skim milk on the formation of $\varepsilon$-( $\gamma$-glutamyl)lysine and the susceptibility of individual proteins towards crosslinking. International Dairy Journal, v. 11, p. 785-793, 2001.

45 SHARMA, R.; ZAKORA, M.; QVIST, K.B. Susceptibility of an industrial $\alpha$-lactalbumin concentrade to crosslinking by microbial transglutaminase. International Dairy Journal, v. 12, p. 1005-1012, 2002a. 
46 SHARMA, R.; ZAKORA, M.; QVIST, K.B. Characteristics of oil-water emulsions stabilisied by an industrial $\alpha$-lactalbumin concentrate, cross-linked before and after emulsification by a microbial transglutaminase. Food Chemistry, v. 79, p. 493-500, 2002b.

47 SINGH, H. Modifications of food proteins by covalent crosslinking. Trends Food Science \& Technology, v. 2, p. 196-200, 1991.

48 TAGUCHI, S.; ARAKAWA, K.; YOKOYAMA, K.; TAKEHANA, S.; TAKAGI, H.; MOMOSE, H. Overexpression and purification of microbial pro-transglutaminase from Streptomyces cinnamoneum and in vitro processing by Streptomyces albogriseolus proteases. Journal of Bioscience and Bioengineering, v. 94, n. 5, p. 478-481, 2002.

49 WILCOX, C.P.; SWAISGOOD, H.E. Modification of the rheological properties of whey protein isolate through the use of an immobilized microbial transglutaminase. Journal of Agricultural and Food Chemistry, v. 50, p. 5546-5551, 2002.

50 WORRATAO, A.; YONGSAWATDIGUL, J. Purification and characterization of transglutaminase from Tropical tilapia (Oreochromis niloticus). Food Chemistry, v. 93, p. 651-658, 2005.

\section{Agradecimentos}

Os autores agradecem à CAPES e ao CNPq pelo auxílio financeiro. 